\title{
Design and Evaluation of Nanosized Tiagabine Bio-Flexy Films Using Zingiber officinale Biopolymer for Soft Palatal Drug Delivery
}

\author{
Sugandha Varshney ${ }^{1 *}$ and NV Satheesh Madhav ${ }^{2}$ \\ ${ }^{1}$ Doon Valley Institute of Pharmacy and Medicine, Karnal, Haryana, India \\ ${ }^{2}$ Faculty of Pharmacy, DIT University, Dehradun, India \\ *Corresponding Author: Sugandha Varshney, Doon Valley Institute of Pharmacy and Medicine, Karnal, Haryana, India.
}

Received: September 17, 2019; Published: October 22, 2019

DOI: $10.31080 / A S M S .2019 .03 .0443$

\begin{abstract}
The objective of this research work was to formulate and evaluate nanosized Tiagabine bio-flexy films comprising of biopolymer isolated from rhizomes of [Zingiber officinale]. The formulations were administered through soft palatal route for brain targeting in order to treat epilepsy. This route bypasses first-pass metabolism in the liver, reduces dose frequency and minimizes drug's side effects. Tiagabine, anticonvulsant drug possesses $t_{1 / 2}: 7$ - 9 hours (low); protein binding: 96\%; water solubility: 22mg/L, acts as selective GABA reuptake inhibitor. Side effects include abdominal pain, pharyngitis, suicidal thoughts and sudden unexpected death. [Zingiber officinale] biopolymer was used to prepare bio-flexy films due to its biodegradability, biocompatibility, non-toxicity, nonirritantancy on soft palatal surface along with inbuilt film ability, mucoadhesive properties. Bio-flexy films were prepared by solvent casting technique. Formulations containing different ratios of nanosized Tiagabine: [Zingiber officinale] biopolymer (1:0.5, 1:1; 1:3, 1:5, 1:6, 1:10) (FZT1-FZT6) were prepared and compared with nanosized Tiagabine loaded Sodium CMC standard flexy films (FET1FET6). The percentage yield of [Zingiber officinale] biopolymer was found to be $32.2 \pm 0.01 \%$. Thickness of formulated bio-flexy films: $0.029 \pm 0.005 \mathrm{~mm}$ to $0.043 \pm 0.003 \mathrm{~mm}$, folding endurance: $125-179$, surface $\mathrm{pH}: 7.00 \pm 0.02$ to $7.00 \pm 0.01$, weight uniformity: 0.001 \pm 0.04 to $0.025 \pm 0.02$, drug content uniformity: $76.6 \% \pm 0.45$ to $84.8 \% \pm 0.34$, swelling percentage: $64 \% \pm 0.2$ to $76 \% \pm 0.1$, percentage moisture uptake: $2.2 \% \pm 0.11$ to $3.5 \% \pm 0.10$, mucoadhesion time: 45 - 150 minutes, microrotation time: $60-180$ minutes. Based on all evaluation parameters, Formulation FZT1 (containing Tiagabine: [Zingiber officinale] biopolymer (1:0.5)) was selected as Best Film as in-vitro release study results revealed prolonged duration of period, $\mathrm{R}^{2}=0.9255, \mathrm{~T}_{50 \%}=25 \mathrm{hrs}$., $\mathrm{T}_{80 \%}=32 \mathrm{hrs}$., Higuchi matrix as best fit model, follows Fiskian diffusion (Higuchi matrix) release mechanism using BITS Software 1.12.Stability study revealed stable bio-flexy films.
\end{abstract}

Keywords: Bio-Flexy Films; Nanosized Tiagabine; Soft Palatal Delivery; Mucoadhesive; [Zingiber officinale] Biopolymer

\section{Abbreviations}

Mm: Millimeters; Hrs: Hours; T1/2: Half Life; Sodium CMC: Sodium Carboxyl Methyl Cellulose; FZT1-FZT6: 6 Bio-Flexy Films Formulations Of Nanosized Tiagabine With [Zingiber officinale] Biopolymer In Ratios Of (1:0.5-1:10); FET1-FET6: 6 Bio-Flexy Film Formulations Of Nanosized Tiagabine With Sodium Carboxyl Methyl Cellulose Standard Polymer In Ratios Of (1:0.5 - 1:10); GIT: Gastro Intestinal Tract; No.: Number; U.V.: Ultraviolet Visible
Spectroscopy; Cm2: Centimeters Square; Abbreviations: Full Forms (Expanded Meaning); Mins: Minutes; Ml: Milliliters; Gm.: Grams; Mg: Milligram; Rpm: Revolutions Per Minute; PDI: Polydispersity Index; Kbr: Potassium Bromide; I.R.: Infra-Red Spectroscopy; DSC: Differential Scanning Calorimetry; NMR: Nuclear Magnetic Resonance; SEM: Scanning Electron Microscopy; CDR: Cumulative Drug Release; T50\%: Time During Which 50\% Drug Is Released; T 80\%: Time During Which 80\% Drug Is Released; RH: Relative Humidity; ICH: International Conference On Harmonization 


\section{Introduction}

The soft palate (velum), a part of oral mucosa, is a novel promising platform cum mucoadhesive site for systemic and local drug delivery. It is a smart drug targeting route to the brain. It possesses non-keratinized histology, unique thickness comparable with buccal mucosa [1]. It provides significant retention of dosage form at site due to non-interference of tongue. Since it lacks taste buds, bitter tasting drugs can be administered by this route. The soft palatal mucosa possesses unique inbuilt characteristics of not interfering with patient's regular routine activities of talking, eating, drinking, etc. It is innervated by Mandibular branch of trigeminal nerve; Lesser palatine nerve; Greater palatine nerve; Nasopalatine nerve; Glossopharyngeal nerve; Motor nerves as well as Middle Meningeal artery, Accessory Meningeal artery, Greater Palatine branch of Maxillary Artery, Ascending Palatine branch of Facial Artery, Ascending pharyngeal artery [2]. It has Thickness: 158 - $224 \mu \mathrm{m}$, pH: $7.34 \pm 0.38$, Blood flow: $0.89 \mathrm{~mL} / \mathrm{min} / \mathrm{cm}$, Surface area: 200 $\mathrm{cm}^{2}$. Soft palatal mucosa is richly vascularized. 4 - 4000 times more permeable than skin. It closes off the nasal passages during swallowing. No mechanical irritation due to its smooth surface, good flexibility, devoid of bones. Drug delivery occurs in controlled, sustained, retentive, systemic manner. It provides optimal site specific delivery as $\mathrm{pH}$ value nearer to blood. Low Enzyme Activity avoids the acid hydrolysis of drug. Enhances the drug bioavailability and provides rapid drug transportation to systemic route. It can deliver steady infusion of drugs over an extended time period because of the function of the soft palate to cover the glottis while swallowing, provides sustained and controlled drug delivery due to the presence of immobile mucosa. First-pass metabolism in liver is bypassed. It provides feasible means of delivering orally inefficient drugs like potent peptide, protein drug molecules. Self-medication is possible with proper patient counseling and easy termination of the drug delivery is achieved by removal of the dosage form from the site. It has high patient compliance. Adverse effects and therapeutic failures frequently associated with intermittent dosing are avoided, drug toxicity is reduced. Drugs having erratic absorption from the stomach or intestine can be administered by this route. It overcomes the inconvenience caused by pain, tissue damage that occurs in drug administration via parenteral route. The soft palatal region being flexible and mobile tissue can be easily accessed for placing the dosage form. When drug in nanosized form is administered by this route, it can directly reach into brain by trigeminal nerve that connects soft palate to brain [3].
Epilepsy is a chronic neurological disorder affecting 65 million people globally as stated by World Health Organization. Every year 2.4 million people are diagnosed with epilepsy. Epilepsy can be Idiopathic i.e., with no identifiable cause or Symptomatic or Secondary Epilepsy i.e., due to known cause such as brain damage, genetic abnormality, head injury, stroke, meningitis, encephalitis, brain tumor etc. There is no cure for epilepsy, but the disorder can be managed with medications and other strategies. It is characterized by recurrent seizures in which involuntary movements involving partial or complete brain occur that might lead to unconsciousness. It occurs due to excessive electrical discharges in brain cells. Two or more unprovoked seizures leads to Epilepsy. There are two types of Neurotransmitters in brain. Excitatory or Glutamatergic Neurotransmitter and Inhibitory or GAB Aminergic Neurotransmitters. Excess of Excitatory neurotransmitter discharges lead to epilepsy.

Antiepileptic Tiagabine available as tablets and capsules dosage forms undergoes First Pass Metabolism in GIT leading to delayed action. Enhances activity of Gamma Amino Butyric Acid (GABA), acts as selective GABA reuptake inhibitor. Side effects include sudden unexpected death in epilepsy. Thus, if its dose and frequency of drug administration are reduced, its side effects can also be minimized.

Synthetic polymers are prepared by harmful chemicals, thus if they are replaced by biopolymers, it will be safer and economical.

In this research work, an inert, biodegradable cost effective biopolymer obtained from [Zingiber officinale] rhizomes was used to avoid toxicity that is by synthetic polymers [4]. [Zingiber officinale] contains 6-Gingerol, 6-Shogaol, 6-Paradoland Sesquiterpene hydrocarbons like Zingiberene, Curcumene, $ß$ - Sesquiphellandrene, E, E$\alpha$-Farnesene, and $\beta$-Bisabolene. It also contains Carbohydrates-5 - 70\%, Starch- 60\%, Proteins- 10\%, Amino Acids as primary metabolites, Fats-10\%, Fibers- 5\%, Inorganic material- 6\%, Residual moisture - 10\%, Essential Oil-1 to $4 \%$, Vitamins like Nicotinic Acid, Vitamin A, Lipids-3 to 8\%, Phytosterols, Minerals and Phenolic Compound [5,6]. Biopolymer serves as a suitable bio-excipient for the formulation of bio-flexy films.

Bio-flexy films were prepared by solvent casting method. Tiagabine is anticonvulsant drug, [Zingiber officinale] biopolymer act as mucoadhesive, film forming cum retarding agent, Pectin was 
used as film initiator, Dextrose, Fructose as flexicizer, Glycerin as plasticizer, Distilled water as solvent.

These formulations were screened for mucoadhesive, mucoretentivity, permeability, in-vitro performance. The optimized formulations showing $\mathrm{t}_{1 / 2}$ of more than $90 \mathrm{hrs}$. were selected as best formulations. Best selected formulations will be further used for In-vivo studies.

Existing epilepsy treatment requires prolonged oral therapy of anticonvulsants API molecules with increased dose frequency mode. This causes unexpected adverse reactions, side effects and withdrawal symptoms in patients due to cumulative dose dumping. Soft palatal route therapy avoids these drawbacks of oral therapy. This study screens the mucoadhesivity, feasibility of isolated biopolymer and also enlightens the potentiality of Oro-Soft Palatal mucosa as a novelistic drug delivery platform for direct brain targeting of drugs in order to elicit Anticonvulsant properly.

\section{Materials and Methods}

DRUG: Tiagabine (obtained from Sun Pharmaceuticals Industries Ltd., Gujarat) POLYMERS: Ginger rhizomes procured from local market Sodium Carboxyl Methyl Cellulose (Central drug House (P) Ltd. New Delhi) All other reagents used were of highest purity and analytical grade. Double distilled water was used throughout the experimental work.

\section{Isolation of biomaterial from [Zingiber officinale] [6]}

Ginger rhizomes were procured from local market. Weighed, 50 gm. of Ginger and crushed. Prepared paste by adding $150 \mathrm{~mL}$ of distilled water. Squeezed extract using muslin cloth, washed with chloroform. Added $50 \mathrm{~mL}$ Acetone, mixed well. Magnetic Stirring for 1 hour, centrifuged at $3500 \mathrm{rpm}$ for 15 minutes, filtered to remove oleoresins. Added $250 \mathrm{~mL}$ of distilled water to residue. Soaked residue in $500 \mathrm{~mL}$ of Propan-2-one for 4 - 5 hours, centrifuged at $3500 \mathrm{rpm}$ for 15 minutes. Biomaterial was collected, subjected to air drying for 24 hours. Powdered biomaterial passed through Sieve No. 120. Optimized the procedure 6 times, calculated \% yield and stored in well closed container for further use.

\section{Physicochemical characterization of isolated biomaterial [7]}

The Physiochemical characterization of isolated biomaterial was performed like color, odor, solubility, melting point and various chemical tests were performed.
- $\quad$ Texture, (b) Color, (c) Odor were examined physically.

- Color Changing Point and Melting Point: Determined by capillary method by using Melting point apparatus. The biopolymer was kept in a capillary tube and it was fitted in a Melting point apparatus and the temperature was determined by means of thermometer.

- Solubility: Determined in different solvents (chloroform, methanol, distilled water, acetone, carbon tetrachloride)

- Test for carbohydrates: Molisch Reagent Test: $2 \mathrm{~mL}$ of biopolymer solution ( $0.1 \mathrm{gm}$ dissolved in $2 \mathrm{~mL}$ of distilled water) was taken in a test tube. 2 drops of Molisch reagent (Solution of $\alpha$-naphthol in 95\% Ethanol) was added. Solution was then poured slowly into a test tube containing $2 \mathrm{~mL}$ of concentrated sulphuric acid. Two layers were formed. Observed color change.

- Test for proteins: Biuret Test: This test determines the presence of peptide bonds in protein content in isolated biomaterial. $2 \mathrm{~mL}$ of biomaterial solution $(0.1 \mathrm{gm}$. dissolved in $2 \mathrm{~mL}$ of distilled water) was taken in a test tube. $1 \mathrm{~mL}$ of sodium hydroxide solution (1\%) followed by $1 \%$ copper (II) sulphate solution was added drop wise. Test tube was then shaken vigorously. Allowed the mixture to stand for 5 minutes and observed the color change. Biuret test is based on the ability of $\mathrm{Cu}$ (II) ions to form a violet-colored chelate complex with peptide bonds (CONH groups) in alkaline conditions. The chelate complex absorbs light at $540 \mathrm{~nm}$ so it appeared violet. Color change was observed.

- Test for starch: $2 \mathrm{~mL}$ of biomaterial solution $(0.1 \mathrm{gm}$. dissolved in $2 \mathrm{~mL}$ of distilled water) was taken in a test tube.1-2 drops of iodine solution was added. Then observed the color change.

- $\quad$ Test for reducing sugar: $2 \mathrm{~mL}$ of biopolymer solution (0.1 gm. dissolved in $2 \mathrm{~mL}$ of Distilled water) was taken in a test tube. Added $1 \mathrm{~mL}$ each of Fehling's A $\left(7 \mathrm{~g} \mathrm{CuSO}_{4} \cdot 5 \mathrm{H}_{2} \mathrm{O}\right.$ dissolved in distilled water containing 2 drops of dilute sulfuric acid) and Fehling's B (35 gm. potassium tartrate, 12 gm. of sodium hydroxide in $100 \mathrm{~mL}$ of distilled water). The test tube was placed in a water-bath at $60^{\circ} \mathrm{C}$. Observed color change.

\section{Spectral studies of isolated biopolymer [6,7]}

\section{IR Spectroscopy}

The IR spectroscopy of isolated biopolymer in solid form was performed by using Potassium Bromide Disc Method. 1mg of sam- 
ple was finely admixed with about $100 \mathrm{mg}$ of Potassium Bromide $(\mathrm{KBr})$ in mortar. Pressure of 10 tons was applied to mixture using hydraulic pump. Small pellet of $1-2 \mathrm{~mm}$ in diameter was formed. The prepared pellet was kept in path of IR radiation and recorded the spectrum within the range of $4000-200 \mathrm{~cm}-1$. IR of pure Tiagabine was also performed.

\section{DSC (differential scanning calorimetry)}

Amount of the heat difference of Sample and Reference was measured against temperature. It was performed for determination of Glass Transition temperature (GTT or Tg). For DSC the Perkin Elmer Instrument, Model-JADE DSC was used, with the Heat flow of $50-250^{\circ} \mathrm{C}$ at the rate of $10^{\circ} \mathrm{C} /$ minute and Nitrogen rate of flow of $20 \mathrm{~mL} /$ minute was used. DSC of pure Tiagabine was also performed.

\section{ZETA sizing and particle size determination}

Zeta Potential values provide an indirect measurement: of net charge on the particles. When charged nanosized particles are dispersed in a liquid, a layer of ions of opposite charge strongly bound to their surface forming a charged thin layer called Stern Layer. This induces the formation of second diffuse out layer, composed of loosely associated ions called Diffusive Ion Layer. These two layers are collectively called Electrical Double Layer. When the nanosized particles moved in liquid phase due to applied electric field, there exists a boundary between the ions in Diffuse Layer that move with the particle and the ions that remain with the bulk dispersant. The Electrostatic Potential at this Slipping plane boundary is Zeta Potential.

\section{NMR (nuclear magnetic resonance) spectral analysis}

Exploits the magnetic properties of atomic nuclei, determines the physical and chemical properties of atoms or the molecules in which they are contained. It relies on the phenomenon of Nuclear Magnetic Resonance and can provide detailed information about the structure, dynamics, reaction state, and chemical environment of molecule. Solvent used was DMSO (Dimethyl Sulfoxide). The spectrometer was connected to flow cell of $5 \mathrm{~mm}$ diameter. High flow rates were applied to the sample, a valve switch was activated to stop the flow for quick measurement. When the valve switches back, the flow cell in the instrument was rinsed again with the reaction mixture. The spectrum was sent to the automation computer where it can be processed and analyzed.

\section{SEM analysis}

Morphological examination of the surface and internal structure of the biomaterial was performed by using a scanning electron microscope (SEM). A small amount of biomaterial was fixed on aluminum studs and it was coated with gold using a sputter coater under vacuum (pressure: $1 \mathrm{~mm} \mathrm{Hg}$ ). The biomaterial was then analyzed by SEM and reported.

Cell-line toxicity study of biopolymer (MTT cytotoxicity assay)

H9c2 cell line (cardiac cells) has been used for this Cell-Line toxicity study. MTT [3-(4, 5-Dimethyl Thiazol-2-yl)-5-Diphenyl Tetrazolium Bromide] is taken up by the viable cells and reduced to Formazan by the "Succinate-tetrazolium reductase" system that belongs to the mitochondrial respiratory chain functioning in metabolically active cells. Formazan formed, is a purple colored waterinsoluble product that is largely impermeable to cell membranes, thus resulting in its accumulation within the healthy cells which is solubilized by adding Dimethyl Sulfoxide (DMSO). The optical density (OD) of purple colored solution developed was read using a conventional ELISA plate reader at $590 \mathrm{~nm}$ (maximum Absorbance). The ability of cells to reduce MTT provides an indication of the mitochondrial integrity and activity, which, in turn, may be interpreted as a measure of viability and/or cell number. The ability of the cells to survive a toxic insult is the basis of this Cytotoxicity assay. Dead cells or their products do not reduce Tetrazolium.

\section{Procedure}

The monolayer cell culture was trypsin zed and the cell count was adjusted to $1.0 \times 10^{5}$ cells/ml using DMEM containing $10 \%$ FBS. To each well of the 96 well microtiter plate, $0.1 \mathrm{ml}$ of the diluted cell suspension (approximately 10,000 cells) was added. After $24 \mathrm{~h}$, when a partial monolayer was formed, the supernatant was flicked off, washed the monolayer once with medium and $100 \mu \mathrm{l}$ of different test concentrations of test drugs were added on to the partial monolayer in microtiter plates. The plates were then incubated at $37^{\circ} \mathrm{C}$ for 3 days in $5 \% \mathrm{CO}_{2}$ atmosphere, and microscopic examination was carried out and observations were noted every 24 $\mathrm{h}$ interval. After $72 \mathrm{~h}$, the drug solutions in the wells were discarded and $50 \mu \mathrm{L}$ of MTT in PBS was added to each well. The plates were gently shaken and incubated for $3 \mathrm{~h}$ at $37^{\circ} \mathrm{C}$ in $5 \% \mathrm{CO}_{2}$ atmosphere. The supernatant was removed and $100 \mu \mathrm{l}$ of propanol was added 
and the plates were gently shaken to solubilize the formed formazan. The absorbance was measured using a microplate reader at a wavelength of $540 \mathrm{~nm}$. The percentage growth inhibition was calculated using the following formula and concentration of test drug needed to inhibit cell growth by $50 \%\left(\mathrm{CTC}_{50}\right)$ values is generated from the dose-response curves for each cell line [8].

In-vitro mucoadhesivity of isolated biopolymer

In-Vitro Mucoadhesivity of isolated [Zingiber officinale] biopolymer was determined by Modified Shear Stress Apparatus. Different concentrations $1 \%, 2 \%, 4 \%, 6 \%, 8 \%$ and $10 \%$ of biopolymer solutions were placed between two glass plates of Modified Shear Stress Apparatus. Subjected to shear stress for assessment for In-Vitro Adhesive Strength in terms of weight required for breaking Adhesive bonds between the Biomaterial and the glass plate after specified contact time from 0 - 30 minutes. The results were reported and graphs were plotted. (Figure 1)

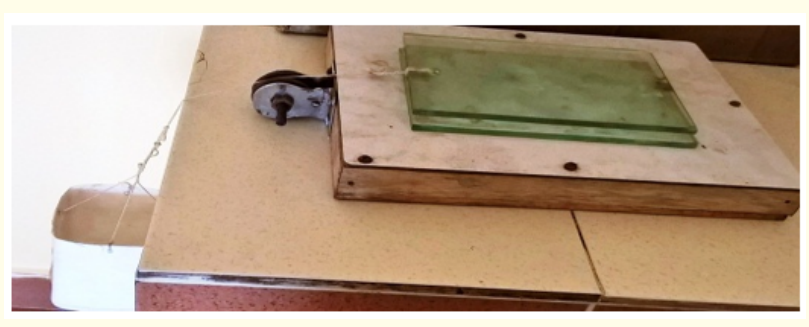

Figure 1: Shear Stress Apparatus for Determination of Mucoadhesive of isolated Biopolymer.

\section{Standard graph of drug}

Preparation of standard curve of tiagabine in distilled water

$10 \mathrm{mg}$ of Tiagabine was dissolved in $30 \mathrm{~mL}$ of distilled water in a $100 \mathrm{~mL}$ volumetric flask and diluted up to the mark with distilled water $(100 \mu \mathrm{g} / \mathrm{mL})$. Dilutions of Concentrations $(0.5,1,2,3,4$ and $5 \mu \mathrm{g} / \mathrm{mL}$ ) were prepared in $10 \mathrm{~mL}$ volumetric flasks. Volume made up to $10 \mathrm{~mL}$ with distilled water $(\lambda \max =257 \mathrm{~nm})$. Absorbance was measured against solvent blank [9].

Preparation of standard curve of tiagabine in phosphate buffer ph 7.4

$10 \mathrm{mg}$ of Tiagabine was dissolved in $30 \mathrm{~mL}$ of Phosphate Buffer $(\mathrm{pH} 7.4)$ in a $100 \mathrm{~mL}$ volumetric flask and diluted up to the mark with Phosphate Buffer $(100 \mu \mathrm{g} / \mathrm{mL})$. Dilutions of Concentrations $(1,2,3,4,5,8,10,20,30,40,50 \mu \mathrm{g} / \mathrm{mL})$ were prepared in $10 \mathrm{~mL}$ volu- metric flasks. Volume was made up to $100 \mathrm{mLwith}$ Phosphate Buffer (pH 7.4) $\left(\lambda_{\max }=396 \mathrm{~nm}\right)$. Absorbance was measured against solvent blank.

\section{Drug excipient interaction studies}

[10] In this study 3 different ratios of Drug: isolated biopolymer i.e., 1:1, 1:3 and 3:1 were taken. Absorbance was measured and compared with that of pure Tiagabine.

- Dry method: Tiagabine: [Zingiber officinale] biopolymer in ratios of $1: 1,1: 3$ and $3: 1$ were taken in three petri dishes in dry form, kept at room temperature for about two hours. The mixtures were then diluted by using $2 \mathrm{~mL}$ Methanol. Measured Absorbance, observed shift in $\lambda_{\text {max }}$ with that of pure Tiagabine and reported.

- Wet method: Tiagabine: [Zingiber officinale] biopolymer in ratios of $1: 1,1: 3$ and 3:1 were taken in three petri dishes. The mixtures were wetted with $1 \mathrm{~mL}$ of distilled water followed by drying at $50^{\circ} \mathrm{C}$ for $30 \mathrm{~min}$ in oven. The mixtures were then diluted by using $2 \mathrm{~mL}$ Methanol. Measured Absorbance, observed shift in $\lambda_{\max }$ with that of pure Tiagabine and reported.

- Colorimetry Method: Tiagabine: [Zingiber officinale] in ratio of 1:1 were mixed with Potassium Permanganate on glass plate. Observed color change, scrapped, Diluted suitably with distilled water, analyzed by UV. Similarly repeated with Drug: Distilled Water and Drug: Potassium Permanganate.

Importance of determination of drug-biopolymer interaction by dry and wet methods

The two methods revealed that no interaction of Drug-Biopolymer occurred either in dry form on in presence of solvent. Since biopolymer was isolated from natural source and used in formulation, it has to be ascertained whether the biopolymer was inert in both dry (during storage) as well as wet (if used in oral drug delivery) conditions. Thus to confirm inertness and non-reactive properties of biopolymer with drug, these two methods were performed. The drug was found to be intact with biopolymer.

Preparation of tiagabine from tiagabine hydrochloride by precipitation method

Tiagabine is available as Tiagabine Hydrochloride salt form. Thus, in order to enhance absorption and bioavailability of drug, to avoid ill-effects it is converted to its pure form by Precipitation 
method. To $100 \mathrm{mg}$ of Tiagabine hydrochloride, $20 \mathrm{~mL}$ of distilled water was added in a test tube and shaken vigorously. Mixture was subjected to sonication for 1 cycle (each cycle of 3 minutes) in ultrasonic bath so nicator. $10 \mathrm{~mL}$ of $1 \mathrm{~N}$ sodium hydroxide solution was incorporated drop wise in above Tiagabine solution. Precipitate was formed at bottom of test tube. Mixture was centrifuged for 15 minutes at $3500 \mathrm{rpm}$. Tiagabine was separated, washed with 10 $\mathrm{mL}$ distilled water and air dried. Isolated Tiagabine was analyzed using U.V. Spectrophotometer.

Nanosizing of drug

Solvent evaporation method

$100 \mathrm{mg}$ Tiagabine was admixed with $5 \mathrm{mg}$ of Fructose, $10 \mathrm{mg}$ of Dextrose and $10 \mathrm{~mL}$ of Methanol in mortar pestle. Sonication of mixture was performed for 5 cycles (180 sec/cycle) in ultrasonic bath so nicator. The mixture was then diluted with $50 \mathrm{~mL}$ distilled water and sonicated up to 15 cycles. Measured \% Transmittance, Absorbance, \% Blockage (100 - \% Transmittance) after every 5 cycles. The residue was then dried and stored for further use [11].

\section{Sonication method}

$100 \mathrm{mg}$ Tiagabine was admixed with $5 \mathrm{mg}$ of Fructose, $10 \mathrm{mg}$ of Dextrose and $10 \mathrm{~mL}$ of Distilled water in mortar pestle. Sonication of mixture was performed for 5 cycles (180 seconds/cycle) in ultrasonic bath so nicator. The mixture was then diluted with $50 \mathrm{~mL}$ distilled water and sonicated up to 15 cycles. Measured \% Transmittance, Absorbance, \% Blockage (100\% Transmittance) after every 5 cycles. The residue was then dried and stored for further use [11]. The main purpose of Nanosizing Tiagabine by two different methods was to compare Novel Sonication Method with published Standard Solvent Evaporation Method.

Nano size range determination by preliminary U.V. spectroscopic method

It is a novel primarily screening method for nano-size range particles by U.V. Spectroscopy. Transmittance is based on the concept of Tyndall Effect. When light of specified wavelength passes through the media containing particles less than or greater than the specified particle range, the \% Blockage represents particles beyond the size range whereas the $\%$ Transmittance is considered that the particles lies above the size range at particular range [11].

Permeation study of tiagabine using M.S. apparatus

Permeation Study of Nanosized Tiagabine was performed by using M.S. Apparatus. Nanosized Tiagabine (10 mg) was added in Donor compartment while Phosphate Buffer (pH 7.4) was filled in Receiver compartment. Egg Shell Membrane was tied over donor compartment. Study was conducted for up to 48 hours. Nanosized Drug would permeate through egg membrane into Phosphate Buf- fer. At specific time intervals ranging from 10 minutes up to 48 hours, samples of $5 \mathrm{~mL}$ were withdrawn and immediately restored with the same volume of fresh phosphate buffer. The amount of drug permeated was assessed by measuring the absorbance at 396 nm using U.V spectrophotometer and compared with that of control i.e., without nanosized drug and reported the same.

Formulation of bio-flexy films (solvent casting method)

$100 \mathrm{mg}$ of Nanosized Tiagabine (Anticonvulsant) was triturated with $50 \mathrm{mg}$ of biopolymer (Mucoadhesive, film forming cum retarding agent) (in ratio of 1:0.5) for 2 minutes using pestle mortar. Added $10 \mathrm{~m}$ of Distilled Water (Solvent). To this dispersion, incorporated $10 \mathrm{mg}$ of Dextrose (Flexicizer), $5 \mathrm{mg}$ of Fructose (Flexicizer) and $10 \mu \mathrm{L}$ of Glycerine (1\% solution v/v) (Plasticizer) with continuous stirring. 0.6 gm. of Pectin (Film Initiator) was added. Mixture was further uniformly triturated for 5 minutes. Volume was made up to $20 \mathrm{~mL}$ using Distilled water. Mixture was subjected to magnetic stirring for 15 minutes, followed by sonication for up to 5 cycles (each cycle 3 minutes). Clear dispersion obtained was poured into petri dish. Kept for drying at room temperature for 24 hours. Removed prepared nanosized drug loaded Bio-flexy film from petri dish. Bio-flexy film formulation obtained was cut in 1 sq. $\mathrm{cm}$ dimension, packed in well closed air tight container for further use. Similarly, six different formulations of nanosized Tiagabine with different isolated biopolymers and Standard Sodium Carboxyl Methyl Cellulose Polymer in different ratios of 1:1, 1:3, 1:5, 1:6 and 1:10 were prepared [12] (Tables 1 and 2).

\begin{tabular}{|l|c|c|c|c|c|c|}
\hline Formulation & FZT1 & FZT2 & FZT3 & FZT4 & FZT5 & FZT6 \\
$\mathbf{( 1 : 0 . 5 )}$ & $(\mathbf{1 : 1 )}$ & $\mathbf{( 1 : 3 )}$ & $\mathbf{( 1 : 5 )}$ & $\mathbf{( 1 : 6 )}$ & $\mathbf{( 1 : 1 0 )}$ \\
\hline $\begin{array}{l}\text { Nanosized } \\
\text { Tiagabine } \\
\text { (mg) }\end{array}$ & 100 & 100 & 100 & 100 & 100 & 100 \\
\hline $\begin{array}{l}\text { [Zingiber } \\
\text { officinale] } \\
\text { biopolymer } \\
\text { (mg) }\end{array}$ & 50 & 100 & 300 & 500 & 600 & 1000 \\
\hline $\begin{array}{l}\text { Dextrose } \\
\text { (mg) }\end{array}$ & 10 & 10 & 10 & 10 & 10 & 10 \\
\hline $\begin{array}{l}\text { Fructose } \\
\text { (mg) }\end{array}$ & 5 & 5 & 5 & 5 & 5 & 5 \\
\hline Glycerine ( $\mu$ l) & 10 & 10 & 10 & 10 & 10 & 10 \\
\hline Pectin (gm.) & 0.6 & 0.6 & 0.6 & 0.6 & 0.6 & 0.6 \\
\hline $\begin{array}{l}\text { Distilled Wa- } \\
\text { ter (mL) }\end{array}$ & 20 & 20 & 20 & 20 & 20 & 20 \\
\hline
\end{tabular}

Table 1: Formulation of Nanosized Tiagabine loaded Bio-Flexy Films using Zingiber officinale Biopolymer. 


\begin{tabular}{|l|c|c|c|c|c|c|}
\hline Formulation & $\begin{array}{l}\text { FET1 } \\
(\mathbf{1 : 0 . 5 )}\end{array}$ & $\begin{array}{l}\text { FET2 } \\
\mathbf{( 1 : 1 )}\end{array}$ & $\begin{array}{c}\text { FET3 } \\
\mathbf{( 1 : 3 )}\end{array}$ & $\begin{array}{c}\text { FET4 } \\
\mathbf{( 1 : 5 )}\end{array}$ & FET5 & FET6 \\
\hline $\begin{array}{l}\text { Nanosized } \\
\text { Tiagabine } \\
(\mathrm{mg})\end{array}$ & 100 & 100 & 100 & 100 & 100 & 100 \\
\hline $\begin{array}{l}\text { Sodium Car- } \\
\text { boxyl Methyl } \\
\text { Cellulose } \\
\text { standard } \\
\text { polymer } \\
\text { (SCMC) (mg) }\end{array}$ & 50 & 100 & 300 & 500 & 600 & 1000 \\
\hline $\begin{array}{l}\text { Dextrose } \\
\text { (mg) }\end{array}$ & 10 & 10 & 10 & 10 & 10 & 10 \\
\hline $\begin{array}{l}\text { Fructose } \\
(\mathrm{mg})\end{array}$ & 5 & 5 & 5 & 5 & 5 & 5 \\
\hline $\begin{array}{l}\text { Glycerine } \\
(\mu \mathrm{l})\end{array}$ & 10 & 10 & 10 & 10 & 10 & 10 \\
\hline Pectin (gm.) & 0.6 & 0.6 & 0.6 & 0.6 & 0.6 & 0.6 \\
\hline $\begin{array}{l}\text { Distilled } \\
\text { Water (mL) }\end{array}$ & 20 & 20 & 20 & 20 & 20 & 20 \\
\hline
\end{tabular}

Table 2: Formulation of Nanosized Tiagabine loaded Flexy Films using Sodium Carboxyl Methyl Cellulose Standard Polymer.

Evaluation of formulated bio-flexy films $[12,13]$

Thickness

The average thickness of formulations was determined using standard digital micrometer and reported with appropriate standard deviation.

\section{Surface pH study}

The formulations were allowed to swell by keeping in contact with $1 \mathrm{ml}$ of distilled water for 1 hour at room temperature. The $\mathrm{pH}$ was measured by bringing the electrode in contact with the surface of film and allowing it to equilibrate for 1 minute. The experiments were performed in triplicate and avg. values were reported. It is essential for formulation (rather than polymeric solution) to be neutral to mucosal surface and compatible with soft palatal $\mathrm{pH}$.

Ex-Vivo mucoadhesion study of formulations by rotating cylinder method

Mucoadhesivity of formulated films was evaluated on intestinal mucosa of Capra aegagrus (i.e., Goat). Bio-flexy films of area $1 \mathrm{~cm}^{2}$ of each formulation were cut down using sharp blade. Tied the goat intestinal mucosa over the rotating basket of I-Dissolution

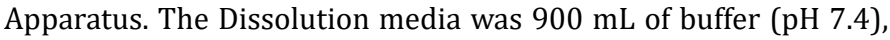
maintained at $37^{\circ} \mathrm{C}$, subjected for rotation at $50 \mathrm{rpm}$. Films were applied over the inner surface of goat intestinal mucosa until they got dislodged. The dislodgement and detachment of films from mucosal surface was observed at regular intervals and reported.

Ex-Vivo Mucoretention Study of Formulations: Bio-flexy films of area $1 \mathrm{~cm}^{2}$ of each formulation were cut down using sharp blade. Tied the Capra aegagrus (Goat) intestinal mucosa over slanting condenser over which buffer was allowed to flow from a burette. It was applied over the inner surface of Goat intestinal mucosa until it got dislodged. The detachment and dislodgement of film from mucosal substrate was noted at regular intervals and reported.

Weight uniformity of formulated nanosized drugs loaded bio-flexy films

Weighed 10 formulations of $1 \mathrm{~cm}^{2}$ diameter. Determined average weight and reported.

Drug content uniformity of formulated nanosized drugs loaded bio-flexy films

Dissolved the films in Phosphate Buffer (pH7.4) (100 mL) for 24 hours with occasional shaking. Diluted $5 \mathrm{~mL}$ of solution with phosphate buffer pH 7.4 up to $20 \mathrm{~mL}$. Filtered through Whatman filter paper of $0.45 \mathrm{~mm}$. The drug content determined by UV analysis at $\lambda_{\max } 257 \mathrm{~nm}$.

Folding endurance of formulated nanosized drugs loaded bio-flexy films

The number of times of film could be folded at the same place without breaking will give the value of the folding endurance. This test was done on randomly selected three bio-flexy films from each Drug: Biopolymer ratio.

Swelling percentage study of formulated nanosized drugs loaded bio-flexy films

$1 \times 1 \mathrm{~cm}^{2}$ sized films were weighed, transferred in petri dish and added $10 \mathrm{~mL}$ of distilled water. After one hour, reweighed the films. Absorption of water and swelling of films caused increased in weights of films. The study was performed for 24 hours. Calculated $\%$ Swelling Index and reported.

Percentage Moisture Uptake (PMU) of formulated nanosized drugs loaded Bio-Flexy Films

Percentage Moisture Uptake of Formulations was determined so as to check the physical stability of the prepared bio-flexy films 
in high moist conditions. Bio-flexy films of $1 \mathrm{~cm}$ diameter were kept in saturated solution of aluminum chloride in desiccator. The humidity inside the desiccator was maintained at 79.5\%. Removed the films after 3 days, weighed, calculated Percentage Moisture Absorption and reported.

Percentage Moisture Uptake $=$

(Final weight of Films-Initial weight of films)

Initial weight of Films

In-Vitro drug release study of formulated nanosized drugs loaded bio-flexy Films

In-Vitro Drug Release Study of Formulations was performed by using Modified M.S. In-Vitro Diffusion Apparatus. Buffer pH 7.4 was filled in 36 vials (receiver compartment). These were kept in thermostatically controlled compartment. Tied Egg membranes to Donor compartment (containing formulations). Donor compartments were inserted into receiver compartments. Temperature was kept constant at $37^{\circ} \mathrm{C}$ with orbital shaker incubator. Sampling was done at regular intervals from $10 \mathrm{~min}$ to 48 hours. Buffer was completely replaced after every sampling. Performed Ultra Violet Spectral analysis of every sample (Figure 2).

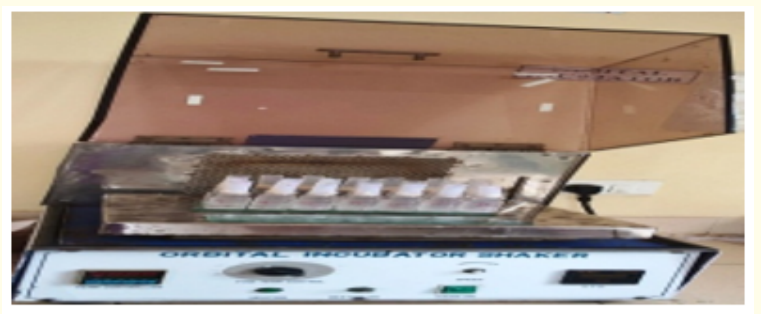

Figure 2: Modified M.S. In-Vitro Diffusion Apparatus.

Stability studies of prepared films as per ICH guidelines (Q1B)

Stability Studies of prepared Films were conducted as per ICH Guidelines Q1B. Stability testing of pharmaceutical product is done to ensure the Efficacy, Safety and Quality of active drug substance and dosage forms and shelf life or expiration period. The Stability Studies of the formulations were performed at $40^{\circ} \mathrm{C} \pm 2{ }^{\circ} \mathrm{C}$ with \pm $45 \pm 5 \% \mathrm{RH}$, at $25 \pm 2^{\circ} \mathrm{C}$ with $60 \pm 5 \% \mathrm{RH}$ and at $2 \pm 5^{\circ} \mathrm{C}$ conditions of temperature and relative humidity for 3 months. Observed for change in $\mathrm{pH}$, Folding Endurance, In-Vitro Drug Release of formulations at room temperature and after stability study $\left(25 \pm 2{ }^{\circ} \mathrm{C}\right.$ with $60 \pm 5 \% \mathrm{RH})$.

\section{Results and Discussion}

This research work explores the potentiality of Oro-Soft Palatal mucosa as a novelistic drug delivery platform for drug delivery to desired site of brain region in order to elicit Anticonvulsant property. In this study nanosized Tiagabine loaded bio-flexy films were formulated and evaluated. The aim of research work is brain targeting of drug via Oro-Soft Palatal mucosa to obtain systemic drug delivery.The rationale of study is to explore the potentialities of soft palatal mucosa as a drug delivery platform. Biopolymer was isolated from [Zingiber officinale] rhizomes. Biopolymer was used to prepare flexy films because of its biodegradability, biocompatibility, non-toxic, non- irritant nature and no reaction on soft palatal surface. Biomaterial possessed in-built film forming properties along with mucoadhesive and mucoretentive properties. Thus, biomaterial was suitable for preparing flexy films for Trans-Soft Palatal delivery.

\section{Yield of isolated biopolymer}

Biopolymer was isolated from natural edible source of [Zingiber officinale] by simplified economic process. The optimization of biopolymer isolation process was repeated six times and the \% yield was calculated. During optimization the results obtained were reproducible with insignificant variation and can be adopted for scaling up in bulk manner. The \% yield of [Zingiber officinale] biopolymer was found to be $32.2 \% \pm 0.01$.

Physicochemical properties of isolated biomaterial

The biomaterial obtained from Rhizomes of [Zingiber officinale] and showed following characteristics:

- Texture: Powder.

- Color: Pale Brown.

- Odor: Characteristic.

- Solubility: Soluble in methanol.

- Color Changing Point: $188 \pm 2^{\circ} \mathrm{C}$.

- Molisch Reagent test for Carbohydrates: Appearance of purple color at interface of the the two layers due to formation of 5-hydroxy methyl furfural. This indicated presence of carbohydrates. 
- $\quad$ Biuret test for Proteins: Color change was observed. Cu (II) ions form a violet-colored chelate complex that absorb light at $540 \mathrm{~nm}$. This indicated presence of proteins.

- $\quad$ Test for Starch: Intense blue black color did not appeared confirmed the absence of Starch in isolated biomaterial.

- $\quad$ Test for Reducing Sugar: brick red precipitate appeared indicating the presence of reducing sugar. It was due to formation of insoluble Copper Oxide.

Spectral studies of isolated biopolymer

IR Spectroscopy

IR Spectroscopy was performed for the isolated biomaterial to determine the presence of Functional Groups in biopolymer. Data showed biopolymer comprises of Carboxyl (-COOH), Hydroxyl $(-\mathrm{OH})$ groups which clearly indicated biopolymers possessed inbuilt mucoadhesive property. IR Peaks of [Zingiber officinale] biopolymer were obtained at $3902 \mathrm{~cm}^{-1}, 3599 \mathrm{~cm}^{-1}, 3011 \mathrm{~cm}^{-1}, 1437$ $\mathrm{cm}^{-1}, 2855 \mathrm{~cm}^{-1}, 2359 \mathrm{~cm}^{-1}$ which indicated functional groups $\mathrm{RCOOH}, \mathrm{RCH}_{2} \mathrm{OH}, \mathrm{RCONH}_{2}, \mathrm{~S}=\mathrm{O}, \mathrm{C}=\mathrm{C}-\mathrm{COOH}, \mathrm{RNH}_{2}$ (Figure 3).

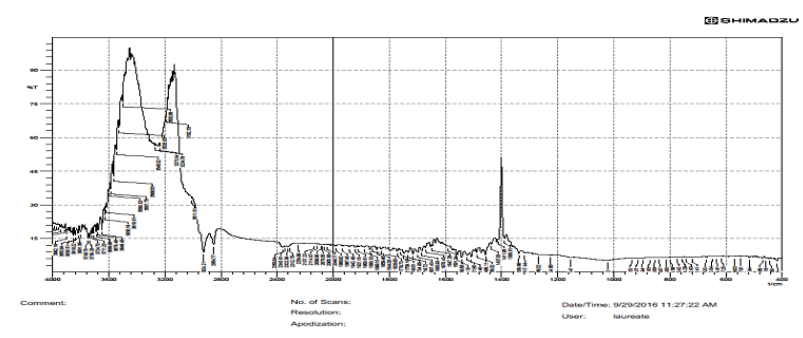

Figure 3: IR Spectra of [Zingiber officinale] biopolymer.

\section{Differential scanning calorimetery (DSC)}

DSC Peak of [Zingiber officinale] biopolymer was obtained at $71.07^{\circ} \mathrm{C}$, Peak Height was $0.5222 \mathrm{~mW}$, Delta H was 20.7489J/g, Onset depicted boiling point at $45.26^{\circ} \mathrm{C}$ and Glass Transition Temperature was $95.06^{\circ} \mathrm{C}$. (Figure 4).

\section{Zeta sizing and particle size determination}

Particle Size Determination graph of [Zingiber officinale] biopolymer showed Peak at 327.8 d.nm, Standard Deviation of 27.90 d.nm, Polydispersity Index (PDI) at $0.962, \mathrm{Z}$ average (d.nm) was at 944.4 , Intensity at $100 \%$, intercept at 1.20 . It depicted monodisperse system (Figure 5).

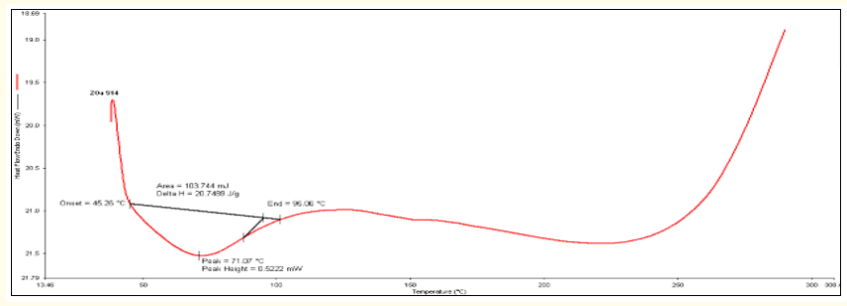

Figure 4: DSC Spectra of [Zingiber officinale] biopolymer.

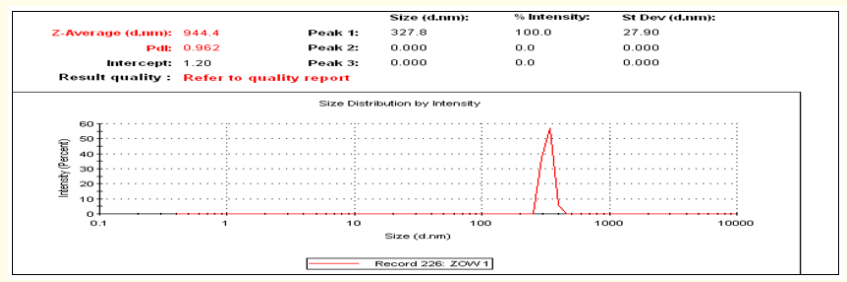

Figure 5: Particle Size Determination of [Zingiber officinale] biopolymer.

\section{Nuclear magnetic resonance spectroscopy (NMR)}

[1] HNMR Spectra of [Zingiber officinale] biopolymer confirmed the presence of carbohydrates residue within the biopolymer extracted as shift of carbohydrate protons were 3 - 6 ppm and the spectra when compared reflected the peak at $3.4441 \mathrm{ppm}$. (Figure 6).

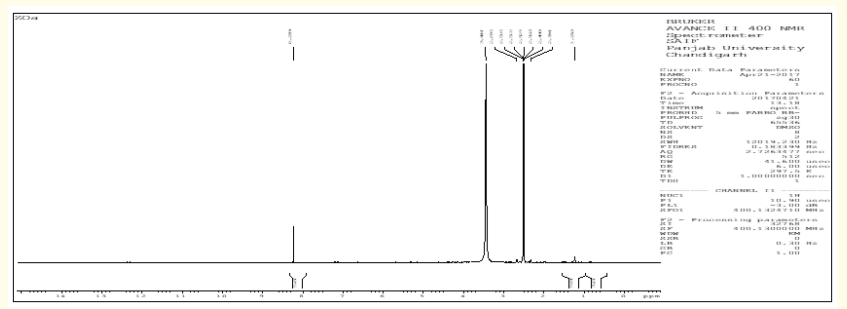

Figure 6: NMR Spectra of [Zingiber officinale] biopolymer.

Scanning electron microscopy (SEM) of isolated biopolymer

SEM image of [Zingiber officinale] biopolymer showed size range of $100 \mu \mathrm{m}$, irregular structure and smooth surface (Figure 7). 


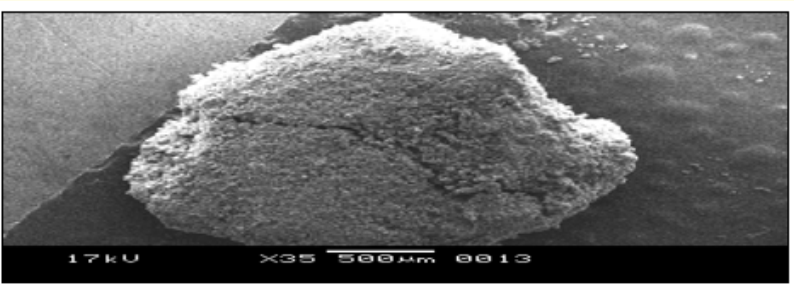

Figure 7: SEM of [Zingiber officinale] biopolymer.

\section{Cell-Line toxicity study data of isolated polymer}

The Cell-Line toxicity for isolated biopolymers was performed by MTT Assay Method using H9c2 Cell-Line. Cell-line toxicity data of [Zingiber officinale] biopolymer in concentrations ranging from $31.25-500 \mu \mathrm{M}$ revealed IC50 $(\mu \mathrm{M})$ of 55.8685 and mean \% cell viability of almost $100 \%$. Hence isolated [Zingiber officinale] biopolymer was found to be safe and devoid of toxicity (Figure 8).

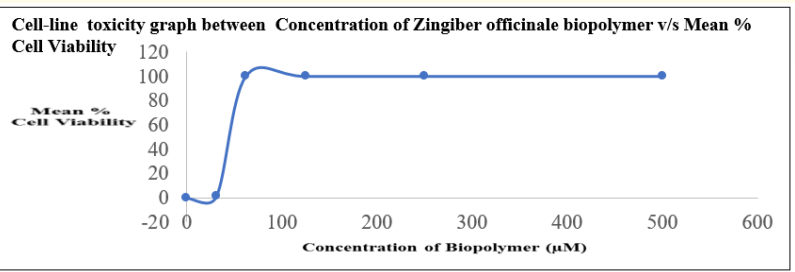

Figure 8: Cell-Line Toxicity Study Data Graph of [Zingiber officinale] Biopolymer.
In-Vitro Mucoadhesivity of Isolated Biopolymers by Shear Stress Method

Isolated [Zingiber officinale] Biomaterial in Concentrations 1\%, $2 \%, 4 \%, 6 \%, 8 \%$ and $10 \%$ were subjected to shear stress for assessment for In-Vitro Adhesive Strength in terms of weight required for breaking Adhesive bonds between the Biomaterial and the glass plate of Modified Shear Stress Apparatus after specified contact time from 0 - 30 minutes. The results were compared with Standard polymer Sodium Carboxyl Methyl Cellulose (Sod CMC) 1\% solution. The results showed significant Mucoadhesion strength of biomaterials as their concentration was increased from 1\% $-10 \%$ with increased contact time from 0 - 30 minutes proportionately. In-Vitro Mucoadhesion Study data of [Zingiber officinale] 1\%, 2\% and $4 \%$ biopolymer concentrations showed significant results with $\mathrm{p}$ value $<0.05$ when compared to $10 \%$ biopolymer concentration and also with 1\% Sodium Carboxyl Methyl Cellulose Standard polymer. Order of Mucoadhesivity of all concentrations of [Zingiber officinale] biopolymer was 10\% [Zingiber officinale] biopolymer > $6 \%$ [Zingiber officinale] biopolymer $>8 \%$ [Zingiber officinale] biopolymer $>4 \%$ [Zingiber officinale] biopolymer $>2 \%$ [Zingiber officinale] biopolymer $>1 \%$ [Zingiber officinale] biopolymer (Table 3).

Spectral studies of pure tiagabine

IR spectra of tiagabine

IR Peaks of Tiagabine were obtained at $1700 \mathrm{~cm}^{-1}, 1580 \mathrm{~cm}^{-1}$, $1049 \mathrm{~cm}^{-1}, 1300 \mathrm{~cm}^{-1}, 1220 \mathrm{~cm}^{-1}$, which indicated functional groups at $\mathrm{RCH}_{2} \mathrm{OH}, \mathrm{N}=\mathrm{O}, \mathrm{S}=0, \mathrm{RCOOH}, \mathrm{RNH}_{2}$ respectively (Figure 9).

\begin{tabular}{|c|c|c|c|c|c|c|c|c|}
\hline \multirow{2}{*}{ S. No. } & \multirow{2}{*}{$\begin{array}{c}\text { Time } \\
\text { (minutes) }\end{array}$} & \multicolumn{6}{|c|}{ Concentration of [[Zingiber officinale]] biopolymer solutions $(\% \mathrm{w} / \mathrm{v})$} & \multirow{2}{*}{$\begin{array}{c}\text { Sodium CMC } \\
1 \%\end{array}$} \\
\hline & & $1 \%$ & $2 \%$ & $4 \%$ & $6 \%$ & $8 \%$ & $10 \%$ & \\
\hline 1. & 0 minute & $\begin{array}{c}20.48 \\
\text { gm. }^{* * *, a} 1\end{array}$ & $186.85 \mathrm{gm}$. & $62.8 \mathrm{gm}^{* * *, a} 1$ & $99.26 \mathrm{gm}$. & $\begin{array}{c}132.05 \\
\text { gm. }\end{array}$ & $165.35 \mathrm{gm}$. & $186.85 \mathrm{gm}$. \\
\hline 2. & 10 minutes & $\begin{array}{c}56.3 \\
\text { gm. }^{* * *, a 1}\end{array}$ & $222.84 \mathrm{gm}$. & $98.77 \mathrm{gm}^{* * *, a 1}$ & $132.12 \mathrm{gm}$. & $\begin{array}{c}151.12 \\
\text { gm. }\end{array}$ & $185.08 \mathrm{gm}$. & $222.84 \mathrm{gm}$. \\
\hline 3. & 20 minutes & $\begin{array}{c}89.5 \\
\text { gm. } .^{* *}, \mathrm{a} 1\end{array}$ & $260.06 \mathrm{gm}$. & $161.2 \mathrm{gm}^{* * *, a 1}$ & $191.35 \mathrm{gm}$. & $\begin{array}{c}188.62 \\
\text { gm. }\end{array}$ & $230.36 \mathrm{gm}$. & $260.06 \mathrm{gm}$. \\
\hline 4. & 30 minutes & $\begin{array}{c}131 \\
\text { gm. }^{* * *, a 1}\end{array}$ & $300.04 \mathrm{gm}$. & 201.48 gm. $^{* * *, a 1}$ & $266.59 \mathrm{gm}$. & $\begin{array}{c}221.5 \\
\text { gm. }\end{array}$ & $268.44 \mathrm{gm}$. & 300.04 gm. \\
\hline
\end{tabular}

Table 3: In-Vitro Mucoadhesivity of [Zingiber officinale] biopolymer by Shear Stress Method.

***: $\mathrm{p}<0.05$ as compared to $10 \% \mathrm{w} / \mathrm{v}$ biopolymer

***, a1: $\mathrm{p}<0.05$ as compared to $1 \% \mathrm{w} / \mathrm{v}$ Sodium Carboxyl Methyl Cellulose Standard Polymer Significance level at 0.05 , One Way ANOVA using T test calculator. 


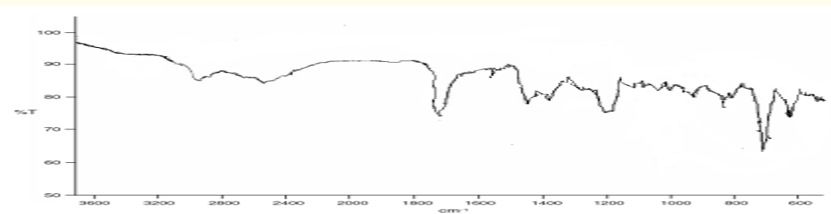

Figure 9: IR Spectra of pure Tiagabine.

\section{DSC spectra of tiagabine}

DSC Peak of Tiagabine was obtained at $90^{\circ} \mathrm{C}$, Tf at $98^{\circ} \mathrm{C}, \mathrm{Tg}$ at $68^{\circ} \mathrm{C}$, Onset at $64^{\circ} \mathrm{C}$ (Figure 10 ).

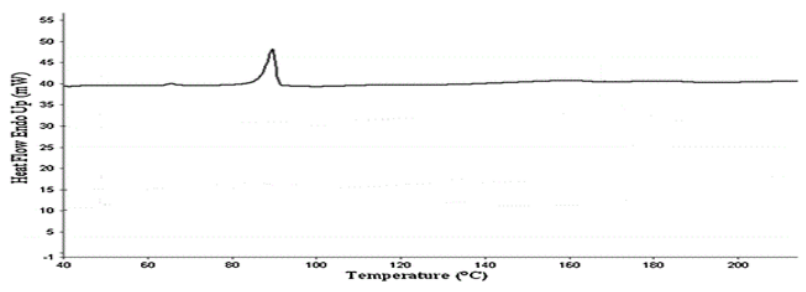

Figure 10: DSC Spectra of pure Tiagabine.

Standard graphs of tiagabine

- Standard graph of tiagabine in distilled water: Calibration Curve of Tiagabine was prepared in Distilled Water. The Standard Graph of Tiagabine was obtained by plotting Concentration versus Absorbance. The Standard Curve of Tiagabine showed linearity at a $\lambda_{\max }$ of $257 \mathrm{~nm}$. $\mathrm{R}^{2}$ value was found to be 0.9993 . (Figure 11 (a))

- Standard graph of tiagabine in phosphate buffer pH 7.4: Calibration Curve of Tiagabine was prepared in Phosphate Buffer pH 7.4. The Standard Graph of Tiagabine was obtained by plotting Concentration versus Absorbance. The Standard Curve of Tiagabine showed linearity at $\lambda_{\max }$ of $396 \mathrm{~nm}$. $\mathrm{R}^{2}$ value was found to be 0.9967. (Figure 11(b))

\section{Drug-excipient interaction study}

Drug-polymer interaction study of the isolated biopolymers was carried out using UV techniques using Wet and Dry methods.
1. Wet method: $\lambda_{\text {max }}$ was observed at $260 \mathrm{~nm}$, and there was no significant difference from that of the pure drug Tiagabine at $257 \mathrm{~nm}$. Therefore, drug-excipient interaction did not occur as there was no shift in $\lambda_{\text {max }}$.

2. Dry method: $\lambda_{\text {max }}$ was observed at $260 \mathrm{~nm}$, and there was no significant difference from that of the pure drug Tiagabine at $257 \mathrm{~nm}$. Therefore, drug-excipient interaction did not occur as there was no shift in $\lambda_{\max }$. Drug polymer interaction was not observed because no change in wavelength of pure drug and drug to biopolymer ratio.

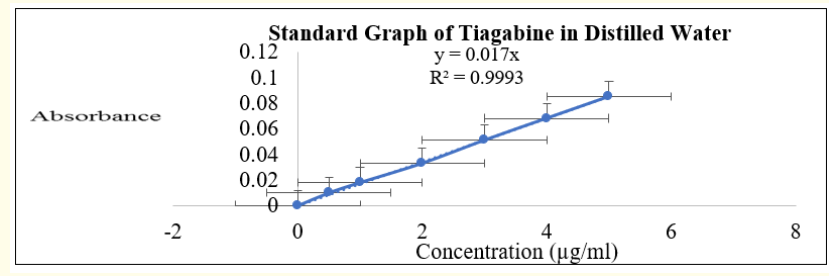

Figure 11(a): Standard Graph of Tiagabine in Distilled Water.

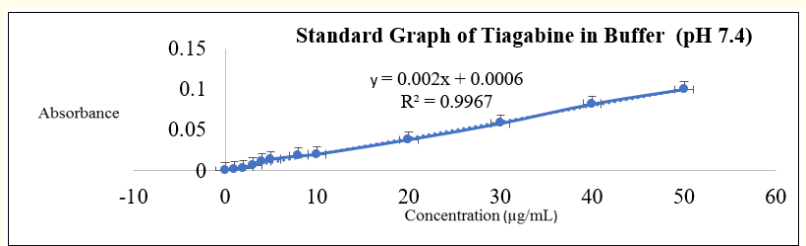

Figure 11(b): Standard Graph of Tiagabine in Phosphate Buffer pH 7.4.

\section{Colorimetry}

$10 \mathrm{mg}$ of drug taken and mixed with biopolymers in ratio of Drug: Polymer 1:1 on glass plate. Added $10 \mu \mathrm{L}$ of $1 \%$ solution of Potassium Permanganate. Observed color change, diluted suitably with distilled water, subjected for U.V. analysis. Scanned in 200 $800 \mathrm{~nm}$ range and determined absorbance. Similarly repeated with Drug: Distilled Water and Drug: Potassium Permanganate. Drug showed color change from pink to brown with Potassium Permanganate while polymer showed no color change. No significant difference in shift of $\lambda_{\max }$ than that of pure drug observed. 
Nanosizing of tiagabine

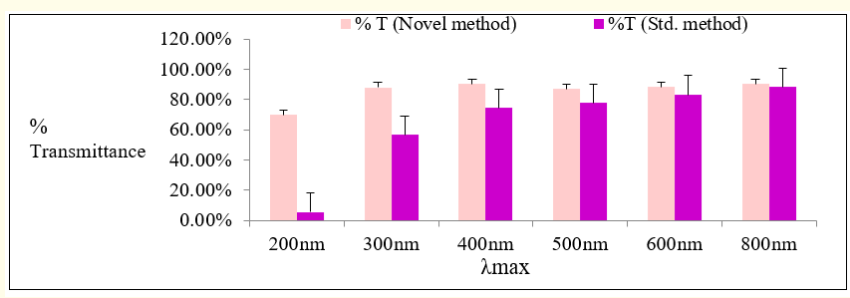

Figure 12: Comparative Graph between \%Transmittance and $\lambda$ max of nanosized Tiagabine (by Novel Sonication and Standard Solvent Evaporation Methods.

\section{Permeation study of tiagabine}

Permeation study of pure and nanosized Tiagabine using M.S. Apparatus revealed that nanosized Tiagabine permeated more through egg membrane than pure Tiagabine (Figure 13).

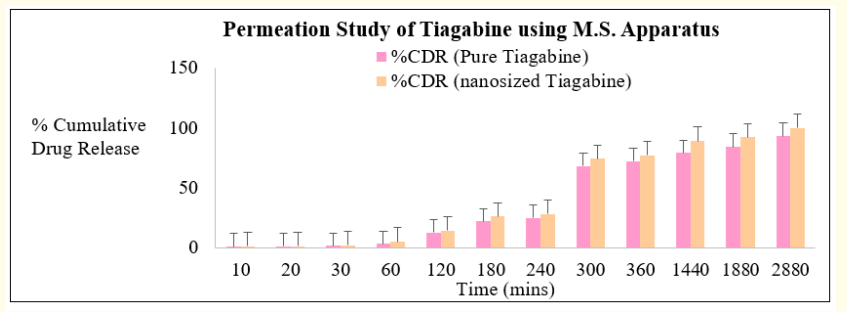

Figure 13: Permeation Study of Tiagabine Using M.S. Apparatus.

Evaluation parameters of formulations

Thickness of formulated bio-flexy films

Thickness of Formulations was measured using Digital micrometer. As polymer concentration was increased, thickness of films increased proportionately. The thickness of nanosized Tiagabine loaded Bio-Flexy films containing [Zingiber officinale] biopolymer (FZT1- FZT6) was found to be in range of $0.029 \pm 0.005 \mathrm{~mm}$ to $0.043 \pm 0.003 \mathrm{~mm}$.

\section{Surface pH of Formulated Bio-flexy Films}

Prepared formulations suitable for soft palatal delivery platform as they are in the range of physiological $\mathrm{pH}$. The Surface $\mathrm{pH}$ of nanosized Tiagabine loaded Bio-Flexy films containing [Zingiber officinale] biopolymer (FZT1- FZT6) was found to be in range of $7.00 \pm 0.02$ to $7.00 \pm 0.01$.

Ex-Vivo mucoadhesion study of formulated bio-flexy films using capra aegagrus (goat) intestinal mucosa

Ex-Vivo Mucoadhesion Study by Rotating Cylinder method revealed that nanosized Tiagabine loaded Bio-Flexy films containing [Zingiber officinale] biopolymer (FZT1-FZT6) showed mucoadhesivity on Capra aegagrus mucosal surface for time period of 45 -150 minutes.

Ex-Vivo microrotation study of formulated bio-flexy films using capra aegagrus (goat) intestinal mucosa

Ex-Vivo Mucoretention Study revealed that nanosized Tiagabine loaded Bio-Flexy films containing [Zingiber officinale] biopolymer (FZT1- FZT6) were mucoretentive on Capra aegagrus mucosal surface for time period of 60 - 180 minutes.

\section{Weight uniformity of formulated bio-flexy films}

The Weight Uniformity of all the Formulations was proportionally increased as polymer concentration was increased. The Weight Uniformity of nanosized Tiagabine loaded Bio-Flexy films containing [Zingiber officinale] biopolymer (FZT1-FZT6) was found to be in range of $0.010 \pm 0.04 \mathrm{mg}$ to $0.025 \pm 0.02 \mathrm{mg}$.

\section{Drug content uniformity of formulated bio-flexy films}

The Drug Content Uniformity of all the Formulations was proportionally increased as polymer concentration was increased. The Drug Content Uniformity of nanosized Tiagabine loaded Bio-Flexy films containing [[Zingiber officinale]] biopolymer (FZT1 - FZT6) was found to be in range of $76.6 \% \pm 0.45$ to $84.8 \% \pm 0.34$.

Folding endurance of formulated bio-flexy films

Folding Endurance of all the formulations was measured and it showed that flexibility was proportionately increased significantly as concentration of polymer in formulation was increased. The Bioflexy films were devoid of brittleness showing significant folding endurance due to presence of dextrose and fructose as excipients in optimized ratio. The Folding Endurance of nanosized Tiagabine loaded Bio-Flexy films containing [Zingiber officinale] biopolymer (FZT1-FZT6) was found to be in range of 125 - 179.

\section{Swelling percentage of formulated bio-flexy films}

The Swelling Percentage of nanosized Tiagabine loaded BioFlexy films containing [Zingiber officinale] biopolymer (FZT1 FZT6) was found to be in range of $64 \% \pm 0.2$ to $76 \% \pm 0.1$. 
Design and Evaluation of Nanosized Tiagabine Bio-Flexy Films Using Zingiber officinale Biopolymer for Soft Palatal Drug Delivery

Percentage moisture uptake of formulated bio-flexy films

The Percentage Moisture Uptake of nanosized Tiagabine loaded Bio-Flexy films containing [Zingiber officinale] biopolymer (FZT1 FZT6) was found to be in range of $2.2 \% \pm 0.11$ to $3.5 \% \pm 0.10$.

In-vitro release study of formulated bio-flexy films by modified M.S. diffusion apparatus

In-Vitro Release Study was performed for up to 48 hours. The In-Vitro drug release pattern for all the formulations were calculated and compared. $\mathrm{T}_{50 \%}$ and $\mathrm{T}_{80 \%}$ values along with the Kinetics data were calculated using BITS software. The release kinetics mechanism was analyzed by comparing $\mathrm{R}^{2}$ values. Formulations were arranged based upon the above parameters is descending manner. The drug release pattern for formulations FZT1-FZT6 containing [Zingiber officinale] biopolymer based on the $\mathrm{T}_{50 \%}$ and $\mathrm{T}_{80 \%}$ was found to be FZT1 (1:0.5) > FZT5 (1:6) > FZT4 (1:5) > FZT6 (1:10)> FZT2 (1:1) > FZT3 (1:3). Based on all above mentioned evaluation parameters, FZT1 (containing Tiagabine: [Zingiber officinale] biopolymer (1:0.5) Bio-flexy film was selected as the Best formulation as it showed significant values of $\mathrm{T}_{50 \%}: 25$ hours., $\mathrm{T}_{80 \%}: 32$ hours and having R2=0.9255, Higuchi Matrix as best fit model, follows Fickian Diffusion (Higuchi Matrix) release mechanism in comparison to other formulations of same biopolymer. (Figure 14) (Table 4).

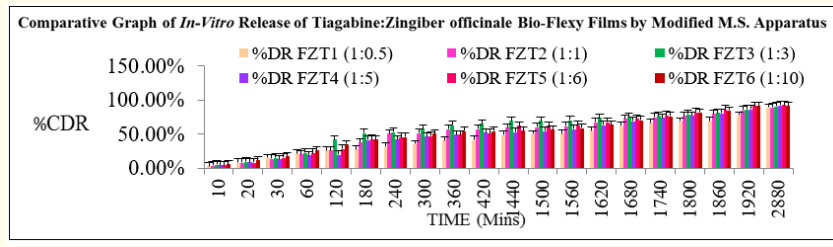

Figure 14: In-Vitro Drug Release Graph of nanosized Tiagabine loaded Bio-Flexy Films using [Zingiber officinale] biopolymer by Modified M.S. Diffusion Apparatus.

\begin{tabular}{|c|c|c|c|c|c|c|c|}
\hline \multicolumn{8}{|c|}{ Release Kinetics Analysis Dynamic Method Formulation of Tiagabine: [Zingiber officinale] Bio-Flexy Films } \\
\hline \multirow[b]{2}{*}{ Formulations } & \multicolumn{5}{|c|}{$\mathbf{R}^{2}$} & \multirow[b]{2}{*}{ Best Fit Model } & \multirow{2}{*}{$\begin{array}{c}\text { Mechanism of } \\
\text { Action }\end{array}$} \\
\hline & $\begin{array}{c}\text { Zero } \\
\text { order }\end{array}$ & $1^{\text {st }}$ order & $\begin{array}{c}\text { Higuchi } \\
\text { Matrix }\end{array}$ & Peppas & $\begin{array}{c}\text { Hixon } \\
\text { Crowell }\end{array}$ & & \\
\hline FZT1 (1:0.5) & 0.8776 & 0.8781 & 0.9255 & 0.9071 & 0.8779 & Higuchi Matrix & $\begin{array}{l}\text { Fickian Diffusion } \\
\text { (Higuchi Matrix) }\end{array}$ \\
\hline FZT2 (1:1) & 0.7626 & 0.7633 & 0.9437 & 0.8916 & 0.7631 & Higuchi Matrix & $\begin{array}{l}\text { Fickian Diffusion } \\
\text { (Higuchi Matrix) }\end{array}$ \\
\hline FZT3 (1:3) & 0.7017 & 0.7025 & 0.9491 & 0.8697 & 0.7022 & Higuchi Matrix & $\begin{array}{l}\text { Fickian Diffusion } \\
\text { (Higuchi Matrix) }\end{array}$ \\
\hline FZT4 (1:5) & 0.8081 & 0.8087 & 0.9374 & 0.9156 & 0.8085 & Higuchi Matrix & $\begin{array}{l}\text { Fickian Diffusion } \\
\text { (Higuchi Matrix) }\end{array}$ \\
\hline FZT5 (1:6) & 0.8265 & 0.8271 & 0.9364 & 0.9190 & 0.8269 & Higuchi Matrix & $\begin{array}{l}\text { Fickian Diffusion } \\
\text { (Higuchi Matrix) }\end{array}$ \\
\hline FZT6 (1:10) & 0.7718 & 0.7725 & 0.9296 & 0.8939 & 0.7722 & Higuchi Matrix & $\begin{array}{l}\text { Fickian Diffusion } \\
\text { (Higuchi Matrix) }\end{array}$ \\
\hline
\end{tabular}

Table 4: Kinetics Release of Tiagabine-[Zingiber officinale] polymer Bio-flexy Films.

The drug release pattern for formulations FET1-FET6 containing Sodium Carboxyl Methyl Cellulose Standard polymer based on the $\mathrm{T}_{50 \%}$ and $\mathrm{T}_{80 \%}$ was found to be FET5 (1:6) > FET1 (1:0.5) $>$ FET2(1:1)> FET3 (1:3)> FET4 (1:5) > FET6 (1:10). Based on all above mentioned evaluation parameters, FET5 (containing Tiagabine: Sodium Carboxyl Methyl Cellulose standard polymer
(1:6)) Flexy film was selected as the Best formulation as it showed significant values of $\mathrm{T}_{50 \%}: 40.66$ hours, $\mathrm{T}_{80 \%}: 43.79$ hours and having $\mathrm{R}^{2}=0.9301$, Higuchi Matrix as best fit model, follows Fickian Diffusion (Higuchi Matrix) release mechanism in comparison to other formulations of same standard polymer (Figure 15) (Table 5). 
Design and Evaluation of Nanosized Tiagabine Bio-Flexy Films Using Zingiber officinale Biopolymer for Soft Palatal Drug Delivery

\begin{tabular}{|c|c|c|c|c|c|c|c|}
\hline elease Kin & naly & imic $N$ & d For & is of & jine: & m CMC Flexy & \\
\hline & & & $\mathbf{R}^{2}$ & & & & \\
\hline Formulations & $\begin{array}{l}\text { Zero } \\
\text { order }\end{array}$ & $1^{\text {st }}$ order & $\begin{array}{c}\text { Higuchi } \\
\text { Matrix }\end{array}$ & Peppas & $\begin{array}{c}\text { Hixon } \\
\text { Crowell }\end{array}$ & Best Fit Model & Mechanism of Action \\
\hline FET1 $(1: 0.5)$ & 0.8894 & 0.8897 & 0.9356 & 0.9300 & 0.8896 & Higuchi-Matrix & Anomalous Transport \\
\hline FET2 (1:1) & 0.8852 & 0.8853 & 0.9324 & 0.8424 & 0.8853 & Higuchi-Matrix & Anomalous Transport \\
\hline FET3 (1:3) & 0.8868 & 0.8868 & 0.9377 & 0.9550 & 0.8868 & $\begin{array}{c}\text { Peppas } \\
\text { Korsmeyer }\end{array}$ & Anomalous Transport \\
\hline FET4 (1:5) & 0.8906 & 0.8908 & 0.9361 & 0.9514 & 0.8908 & $\begin{array}{c}\text { Peppas } \\
\text { Korsmeyer }\end{array}$ & Anomalous Transport \\
\hline FET5 (1:6) & 0.8360 & 0.8363 & 0.9301 & 0.9084 & 0.8362 & $\begin{array}{c}\text { Higuchi- } \\
\text { Matrix }\end{array}$ & $\begin{array}{l}\text { Fickian Diffusion } \\
\text { (Higuchi Matrix) }\end{array}$ \\
\hline FET6 (1:10) & 0.8960 & 0.8962 & 0.9372 & 0.9692 & 0.8961 & $\begin{array}{c}\text { Peppas } \\
\text { Korsmeyer }\end{array}$ & Anomalous Transport \\
\hline
\end{tabular}

Table 5: Kinetics Release of Tiagabine-Sodium CMC Flexy Films.

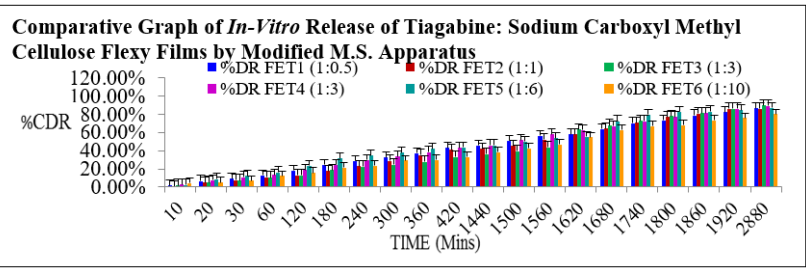

Figure 15: In-Vitro Drug Release Graph of nanosized Tiagabine loaded Bio-Flexy Films using Sodium Carboxyl Methyl Cellulose standard polymer by Modified M.S. Diffusion Apparatus.

Stability studies of formulated nanosized drugs loaded bioflexy films as per ich guidelines $q 1 \mathbf{b}$

Stability studies were conducted as per ICH Guidelines Q1B. Stability testing of pharmaceutical product is done to ensure the efficacy, safety and quality of active drug substance and dosage forms and shelf life or expiration period. The stability studies of the formulations were conducted at $40^{\circ} \mathrm{C} \pm 2 \mathrm{oC}$ and $\pm 45 \pm 5 \% \mathrm{RH}$, $25^{\circ} \mathrm{C} \pm 2 \mathrm{oC}$ and $60 \pm 5 \% \mathrm{RH}$ and $2^{\circ} \mathrm{C} \pm 5 \mathrm{oC}$ temperature and $\mathrm{RH}$ values respectively period of three months. In-vitro drug release, Folding Endurance, Surface $\mathrm{pH}$ of formulations was determined at room temperature and after stability study $\left(25^{\circ} \mathrm{C} \pm 2 \mathrm{oC}\right.$ and $60 \pm$ $5 \% \mathrm{RH}$ ). Bio-flexy films were found to be stable (Figure 16).

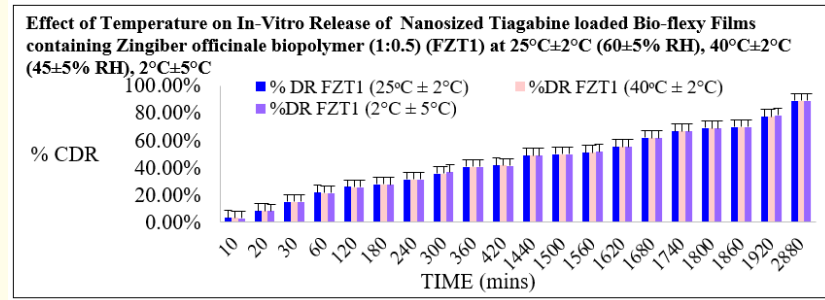

Figure 16: Stability Study Graph of Best Formulations of nanosized Tiagabine loaded Bio- Flexy Films containing [Zingiber officinale] biopolymer.

\section{Conclusion}

The conventional oral therapy for epilepsy leads to significant drug accumulation and economic burden in patients. This research enlightens the potentiality of Oro-Soft Palatal mucosa as a novelistic platform for delivering drug to desired site of brain region so as to elicit Anticonvulsant property. The purpose of study is to formulate and evaluate nanosized Tiagabine loaded bio-flexy films consisting of novel biopolymer isolated from [Zingiber officinale] rhizomes. Biopolymer was biodegradable, inert, showed film ability, mucoadhesivity, mucoretentivity properties. Ratios were chosen at six levels for Drug: Biopolymer (1:0.5 to 1:10) and six levels for Drug: Sodium Carboxyl Methyl Cellulose (1:0.5 to 1:10) for formu- 
lating flex films. Anticonvulsant Tiagabine unidirectional bio-flexy films were formulated by Solvent Casting Method. The percentage yield of [Zingiber officinale] biopolymer: $32.2 \% \pm 0.01$, color: pale brown, odour: characteristic, solubility: methanol, color changing point: $188^{\circ} \mathrm{C} \pm 2$, showed presence of proteins and carbohydrates. Thickness of nanosized Tiagabine loaded bio-flexy films containing [Zingiber officinale] biopolymer (FZT1- FZT6): $0.029 \pm 0.005$ $\mathrm{mm}$ to $0.043 \pm 0.003 \mathrm{~mm}$, Folding Endurance: 125 - 179, Surface pH: $7.00 \pm 0.02$ to $7.00 \pm 0.01$, Weight Uniformity: $0.010 \pm 0.04$ to $0.025 \pm 0.02$, Drug Content Uniformity: $76.6 \% \pm 0.45$ to $84.8 \%$ \pm 0.34 , Swelling Percentage: $64 \% \pm 0.2$ to $76 \% \pm 0.1$, Percentage Moisture Uptake (PTU): $2.2 \% \pm 0.11$ to $3.5 \% \pm 0.10$. Mucoadhesion time: 45 - 150 minutes, Mucoretention time: 60 -180 minutes. The drug release pattern for formulations FZT1-FZT6 containing [Zingiber officinale] biopolymer based on the $\mathrm{T}_{50 \%}$ and $\mathrm{T}_{80 \%}$ was found to be FZT1 (1:0.5) > FZT5 (1:6) > FZT4 (1:5) > FZT6 (1:10)> FZT2 (1:1) > FZT3 (1:3). In-vitro drug release study data revealed that drug loaded formulations showed sustained release behavior. Graph was plotted between \%CDR and time, the $\mathrm{R}^{2}$ value, $\mathrm{T}_{50 \%}$ and $\mathrm{T} 80 \%$ were calculated from graph. Based on all evaluation parameters, FZT1 (containing Tiagabine: [Zingiber officinale] biopolymer (1:0.5)) Bio-flexy film having $R^{2}=0.9255$, Higuchi Matrix as best fit model, follows Fiskian Diffusion (Higuchi Matrix) release mechanism, $\mathrm{T}_{50 \%}: 25$ hrs., $\mathrm{T}_{80 \%}: 32 \mathrm{hrs}$. using BITS Software 1.12. Stability study revealed stable bio-flexy films with no significant change in physical appearance and stable $\mathrm{pH}$. Prepared formulations of Tiagabine loaded bio-flexy films containing [Zingiber officinale] biopolymer were suitable for Soft Palatal Delivery.

This research is an approach to deliver antiepileptic molecules to brain at lesser dose than oral dose to the patients by completely bypassing oral therapy.

\section{Acknowledgement}

We wish to acknowledge Mr. Anuj Aggarwal (Chairman, DIT University), Prof. K.K. Raina (Vice Chancellor, DIT University) for providing platform for conducting the research work.

\section{Bibliography}

1. URL (2014).

2. URL (2014).

3. Shakya P., et al. "Palatal mucosa as a route for Systemic Drug Delivery: a Review". Journal of Controlled Release 151 (2011): 2-9.
4. Nilani P. "Formulation and Evaluation of Polysaccharide Based Biopolymer - an Ecofriendly Alternative for Synthetic Polymer". Journal of Pharmaceutical Sciences and Research 2.3 (2010):178-184.

5. Qin FF and Xu H L. "Active Compounds in Ginger and their Therapeutic use in Complimentary Medication". Medicinal and Aromatic Plant Science and Biotechnology 2.2 (2008): 72-78.

6. Satheesh Madhav N V., et al. "Formulation and Evaluation of Nimesulide Bio-Micro Dwarfs using A Novel Bio-retardant from the Rhizomes of [Zingiber officinale]". International Journal of Pharmaceutical Technology Research 3.1 (2011): 221224.

7. Satheesh Madhav N V., et al. Filed an Indian Patent on Development of flexi Bio-adhesive Film loaded with nanosized Zidovudine for Brain specificity via novelistic Soft Palatal route (2013).

8. Francis D., et al. "Rapid colorimetric assay for cell growth and survival modifications the Tetrazolium dye procedure giving improved sensitivity and reliability". Journal of Immunological Methods 89 (1986): 271-277.

9. Patil S., et al. "Method Development and Validation for Quantitative Analysis of TIGABINE HCL by Ultraviolet Spectrophotometry". International Journal of Chemical Sciences 6.1 (2008): 413-416.

10. Satheesh Madhav N V., et al. Filed an Indian Patent on Development of flexi Bio-Adhesive Film loaded with nanosized Zidovudine for Brain specificity via novelistic Soft Palatal route (2013).

11. Varley H. Introductory Collection of Specimens and some General Techniques, Practical Clinical Biochemistry, 4th Edition, New Delhi, C.B.S. Publishers and Distributors (2005): 21-29.

12. Karki S., et al. "Thin films as an emerging Platform for Drug Delivery". Asian Journal of Pharmaceutical Sciences 11 (2016): 559-574.

13. Hearnden N. "New developments and opportunities in oral mucosal drug delivery for local and systemic disease". Drug Delivery Review 64 (2012):16-28.

\section{Volume 3 Issue 11 November 2019 (C) All rights are reserved by Sugandha Varshney and NV Satheesh Madhav.}

